\title{
Design of Robust Current Controller for Two-Level 12-Pulse VSC-based STATCOM
}

\author{
M. Janaki, ${ }^{1}$ R. Thirumalaivasan, ${ }^{1}$ and Nagesh Prabhu ${ }^{2}$ \\ ${ }^{1}$ School of Electrical Engineering, VIT University, Vellore 632014, India \\ ${ }^{2}$ Department of Electrical Engineering, Canara Engineering College, Mangalore 574219, India
}

Correspondence should be addressed to M. Janaki, janaki.m@vit.ac.in

Received 2 November 2010; Revised 22 March 2011; Accepted 6 April 2011

Academic Editor: Jose Pomilio

Copyright (c) 2011 M. Janaki et al. This is an open access article distributed under the Creative Commons Attribution License, which permits unrestricted use, distribution, and reproduction in any medium, provided the original work is properly cited.

\begin{abstract}
The static synchronous compensator (STATCOM) is a shunt connected voltage source converter (VSC) based FACTS controller using GTOs employed for reactive power control. A typical application of a STATCOM is for voltage regulation at the midpoint of a long transmission line for the enhancement of power transfer capability and/or reactive power control at the load centre. The PI controller-based reactive current controller can cause oscillatory instability in inductive mode of operation of STATCOM and can be overcome by the nonlinear feedback controller. The transient response of the STATCOM depends on the controller parameters selected. This paper presents a systematic method for controller parameter optimization based on genetic algorithm (GA). The performance of the designed controller is evaluated by transient simulation. It is observed that the STATCOM with optimized controller parameters shows excellent transient response for the step change in the reactive current reference. While the eigenvalue analysis and controller design are based on D-Q model, the transient simulation is based on both D-Q and 3-phase models of STATCOM (which considers switching action of VSC).
\end{abstract}

\section{Introduction}

The concept of flexible AC transmission system (FACTS) envisages the use of advances in power electronics technology to achieve flexibility of system operation together with fast and reliable control [1]. Fast control over the reactive power can allow secure loading of transmission lines nearer to their thermal limits, regulate the voltage, and improve system damping. The availability of high-power gate turn off (GTO) thyristors has led to the development of STATCOM.

The STATCOM is a VSC based FACTS device used for shunt reactive power compensation making use of gate turn off (GTO) power semiconductor devices. The VSC is connected to the system bus through an interfacing reactance, which is the leakage reactance of the coupling transformer $[2,3]$. The STATCOM is connected at the midpoint of long transmission line to regulate the voltage and enhance the power transfer capability. The major advantages of the STATCOM over the fixed capacitor-thyristor controller reactor- (FC-TCR-) type SVC are $[4,5]$ :
(1) a significant reduction in size can be achieved because of the reduced number of passive elements and their smaller size,

(2) the STATCOM can supply required reactive current even at low values of bus voltages while the reactive current capability of the FC-TCR at its limit varies linearly with the voltage.

In this paper a 2-level, 12-pulse voltage source converter (VSC) is considered for STATCOM configuration with type2 controller. The type- 2 controller regulates the reactive current output of STATCOM by adjusting the phase angle of the converter output voltage relative to the bus voltage $[1-3,6]$.

The PI controller-based reactive power control with feedback (from the reactive current) can destabilize the system while operating in inductive mode [6]. Schauder and Mehta [2] propose a non linear feedback controller to overcome the problem of instability in the inductive mode of operation. However, the response of PI controller with state variable feedback mainly depends on the controller parameters that 


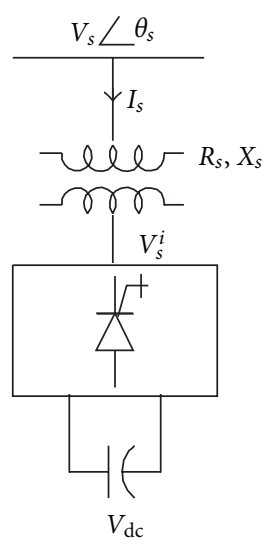

Schematic

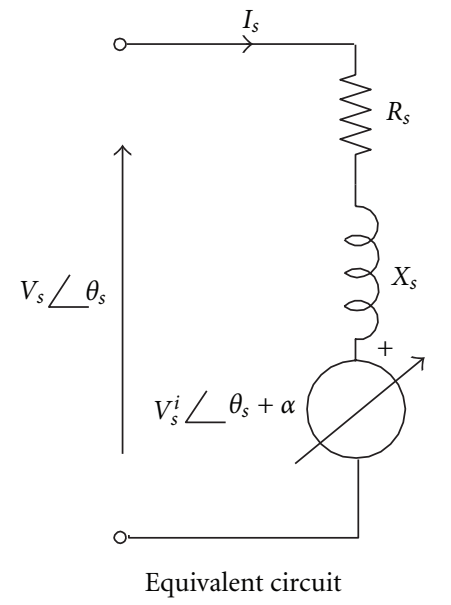

Equivalent circuit
FIgURE 1: STATCOM shunt FACTS controller.

are selected. The objective of this paper is to present a systematic method for controller parameter optimization based on genetic algorithm (GA), while ensuring stability and improvement of transient response.

This paper is organized as follows. Section 2 describes the modeling of STATCOM. The design of reactive current controller is explained in Section 3. The GA-based optimization of controller parameters is described in Section 4, Section 5 gives the conclusions.

\section{Modeling of STATCOM}

The schematic of STATCOM is shown in Figure 1. The STATCOM is connected to the bus (with voltage $V_{s}$ ) through a coupling transformer with resistance and reactance of $R_{s}$ and $X_{s}$, respectively. In the power circuit of a STATCOM, the converter has either a multipulse and/or a multilevel configuration. Here the STATCOM is realized by 12-pulse two-level configuration.

The detailed three-phase model of a STATCOM is developed by modeling the converter operation by switching functions, [6-8]. The modeling of two-level VSC based on switching functions is discussed in detail in [6] and it is not repeated here.

2.1. Mathematical Model of STATCOM in D-Q Frame of Reference $[7,9]$. When switching functions are approximated by their fundamental frequency components neglecting harmonics, STATCOM can be modeled by transforming the three-phase voltages and currents to D-Q variables using Kron's transformation [10]. The STATCOM can be represented functionally, as shown in Figure 1. The magnitude control of converter output voltage $V_{s}^{i}$ is the function of DC voltage $V_{\mathrm{dc}}$ for type-2 converters [2,6]. The converter output voltage can be represented in the D-Q frame of reference as

$$
\begin{gathered}
V_{s}^{i}=\sqrt{V_{s D}^{i}{ }^{2}+V_{s Q}^{i}{ }^{2}}, \\
V_{s D}^{i}=k V_{\mathrm{dc}} \sin \left(\theta_{s}+\alpha\right), \\
V_{s Q}^{i}=k V_{\mathrm{dc}} \cos \left(\theta_{s}+\alpha\right),
\end{gathered}
$$

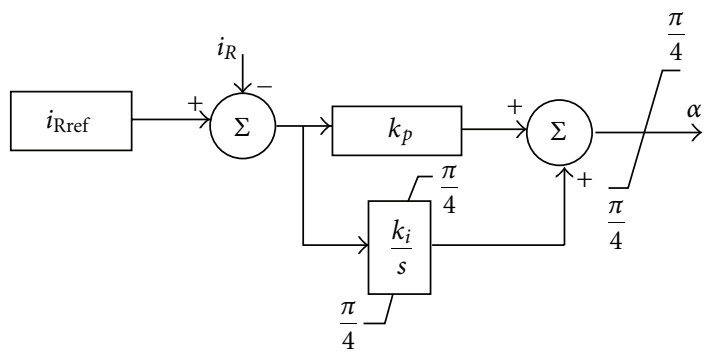

FIgURE 2: Type-2 controller for 2-level VSC based STATCOM.

where $\theta_{s}$ is the phase angle of bus voltage. $\alpha$ is the angle by which the fundamental component of converter output voltage leads the STATCOM bus voltage $V_{s}$.

$k$ is the modulation index (constant for a two-level converter with fundamental frequency modulation and $180^{\circ}$ conduction mode) and is given by $k=2 \sqrt{6} / \pi$ for a 12 -pulse converter.

The following equations in the $\mathrm{D}-\mathrm{Q}$ variables can be given for describing STATCOM:

$$
\begin{aligned}
\frac{d I_{s D}}{d t} & =-\frac{R_{s} \omega_{B}}{X_{s}} I_{s D}-\omega_{o} I_{s Q}+\frac{\omega_{B}}{X_{s}}\left[V_{s D}-V_{s D}^{i}\right], \\
\frac{d I_{s Q}}{d t} & =\omega_{o} I_{s D}-\frac{R_{s} \omega_{B}}{X_{s}} I_{s Q}+\frac{\omega_{B}}{X_{s}}\left[V_{s Q}-V_{s Q}^{i}\right], \\
\frac{d V_{\mathrm{dc}}}{d t} & =-\frac{\omega_{B}}{b_{c}} I_{\mathrm{dc}}-\frac{\omega_{B}}{b_{c} R_{p}} V_{\mathrm{dc}},
\end{aligned}
$$

where

$$
i_{\mathrm{dc}}=-\left[k \sin \left(\theta_{s}+\alpha\right) I_{s D}+k \cos \left(\theta_{s}+\alpha\right) I_{s Q}\right] .
$$

$I_{s D}, I_{s Q} \mathrm{D}-\mathrm{Q}$ components of STATCOM current.

The real and reactive currents are defined as

$$
\begin{aligned}
& I_{P}=I_{s D} \sin \left(\theta_{s}\right)+I_{s Q} \cos \left(\theta_{s}\right), \\
& I_{R}=-I_{s D} \cos \left(\theta_{s}\right)+I_{s Q} \sin \left(\theta_{s}\right) .
\end{aligned}
$$

Values of $I_{P}$ and $I_{R}$ result in positive values when the STAT$\mathrm{COM}$ is absorbing real and reactive power.

2.2. STATCOM Current Control (Two-Level VSC). With a 2level VSC, the reactive current control can be achieved by varying $\alpha$ alone (refer Figure 2). When STATCOM regulates the Bus voltage, the reactive current reference $i_{\text {Rref }}$ in Figure 2 is obtained as the output of the bus voltage controller. However, in the present study $i_{\text {Rref }}$ is kept constant.

In this controller, the modulation index $k$ is constant. The capacitor voltage is not regulated but depends upon the phase difference between the converter output voltage and the bus voltage. The reactive current control is effected by converter output voltage magnitude (which is a function of DC voltage) and achieved by phase angle control $[2,6]$. This causes the variation of capacitor voltage over a small range with change in operating point. 
TABLE 1: Eigenvalues with PI controller.

\begin{tabular}{lc}
\hline Capacitive region $i_{R}=-1$ & Inductive region $i_{R}=1$ \\
\hline-834.58 & -775.36 \\
$-81.819 \pm j 1429.8$ & $12.969 \pm j 1485.8$ \\
-10 & -10 \\
-9.9137 & -9.9137 \\
\hline
\end{tabular}

\section{Reactive Current Controller Design}

3.1. PI Controller without Nonlinear State Variable Feedback. In this section we investigate the design of the reactive current controller. The reactive current of the STATCOM depends on the difference between the bus voltage and the converter output voltage. To simplify the design procedure we design the reactive controller assuming the voltage at STATCOM bus is constant (neglecting the dynamics in the transmission network). The eigenvalue analysis is performed by linearizing the system represented by Figure 1 and described by (1)-(4) for capacitive and inductive mode of operation of STATCOM and are given in Table 1. It is to be noted that the system is unstable in the inductive mode of operation of STATCOM.

The movement of the critical eigenvalues for operating points in the inductive region and capacitive region when a PI controller (refer Figure 2.) is used is shown in Figure 3. Referring to Figure 3 it is observed that in the inductive region the poles move towards the imaginary axis resulting in oscillatory instability. The instability in the inductive mode of operation of a STATCOM is also reported in the literature $[2,6]$.

As detailed in [3], the condition for stability can be expressed as

$$
i_{R}<\frac{\omega C}{k} V_{\mathrm{dc}}
$$

The above condition is always satisfied when $i_{R}<0$ (when the converter is operating in the capacitive mode). Thus, the problem of instability can arise only while operating in the inductive mode and is also verified in the present study.

The important point is that the variation of locations of zeros with the operating point, the angle of departure for this complex mode varies from 0 to $-180^{\circ}$ as the operating point is changed [3]. Thus design of a compensator in cascade with the PI controller which is suitable for all operating points is also difficult.

It is to be noted that the system is unstable in the inductive mode of operation. To validate the linearized analysis (which neglects harmonics in the switching functions) and to check the performance for large deviations from an operating point, the transient simulation of a 12-pulse 3phase STATCOM is carried out using MATLAB-SIMULINK. The action of the converter is modeled using the switching functions (switching instants are obtained from $\theta_{s}$ and the controller output $\alpha)[3,6,11]$. The instability predicted by linearized analysis in the inductive region when a PI

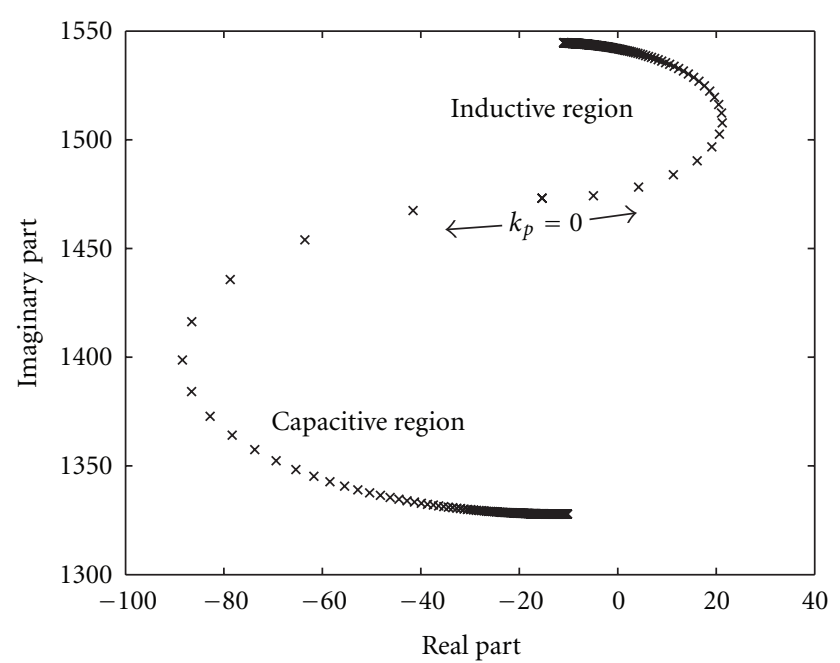

Figure 3: Movement of the critical eigenvalues with PI controller for $k_{p}=0-10$ and $k_{i} / k_{p}=10$.

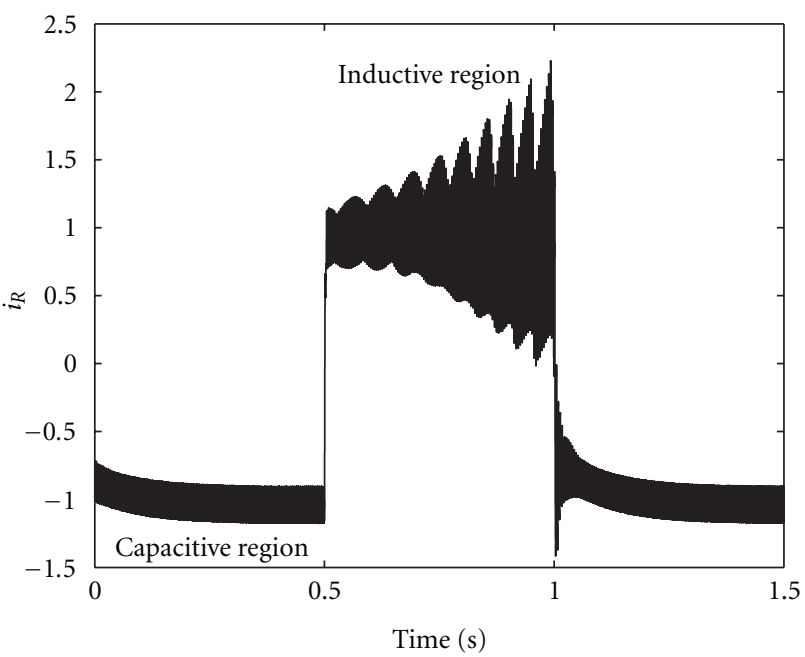

FIGURE 4: Step response of STATCOM with PI controller.

controller is used is also brought out by simulation as shown in Figure 4.

3.2. PI Controller with Nonlinear State Variable Feedback. described and Mehta [2] propose a nonlinear feedback controller to overcome the problem of instability in the inductive mode of operation of STATCOM. The block diagram of the controller is shown in Figure 5.

It is to be noted that the nonlinear controller is active only when $i_{R}>(\omega C / k) V_{\mathrm{dc}}$ and also only during a transient. In steady state, (when $V_{\mathrm{dc}}$ is a constant), the output of the multiplier in nonlinear feedback is zero.

The root locus of the critical eigenvalues with nonlinear feedback controller for inductive and capacitive mode of operation is shown in Figure 6.

It is observed from the root locus plot that the critical modes are stable. 


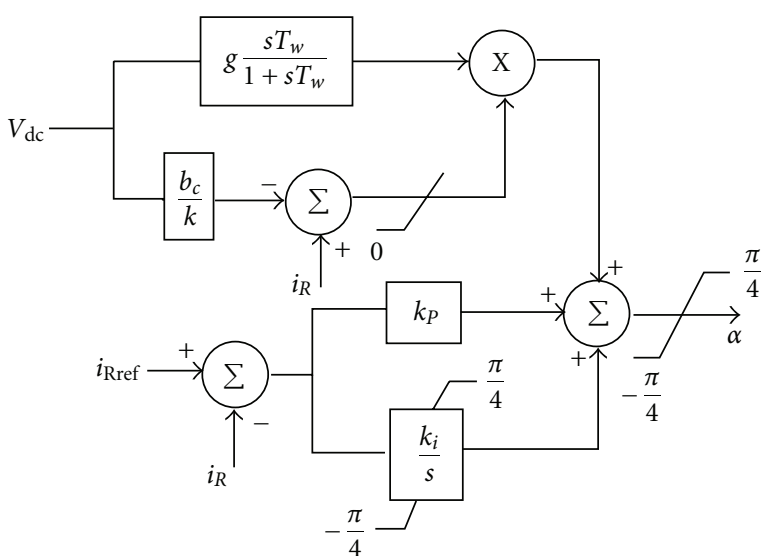

FIgURE 5: Nonlinear feedback controller.

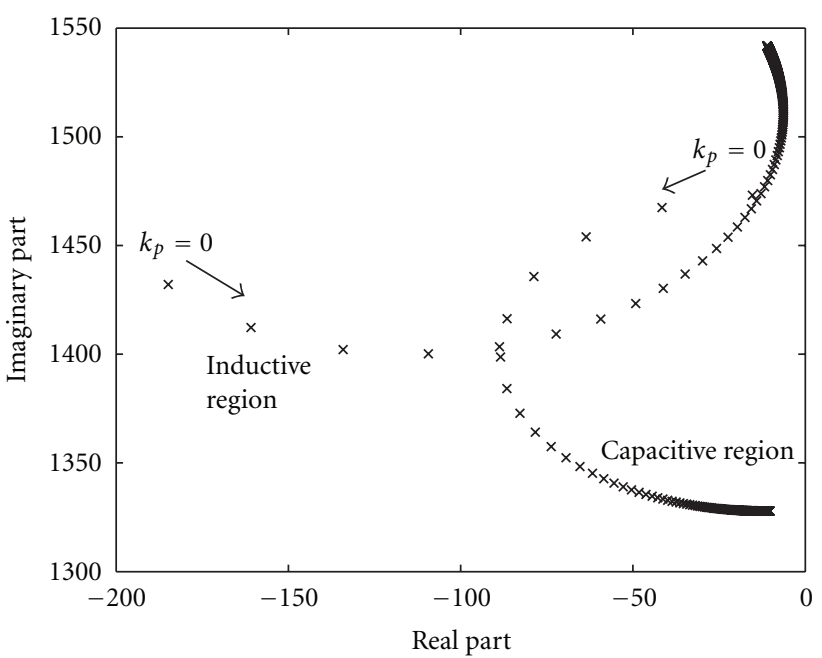

Figure 6: Root locus with nonlinear feedback for $k_{p}=0-10$ and $k_{i} / k_{p}=10$.

TABLE 2: Eigenvalues with nonlinear feedback.

\begin{tabular}{lc}
\hline Capacitive region $i_{R}=-1$ & Inductive region $i_{R}=1$ \\
\hline-834.58 & -1173.2 \\
$-81.819 \pm j 1429.8$ & $-102.73 \pm j 1400.7$ \\
-10 & $-7.3766 \pm j 4.3491$ \\
-9.9137 & \\
\hline
\end{tabular}

The eigenvalues of the system with nonlinear feedback and suboptimal controller parameters [6] are given in Table 2. The suboptimal controller parameters [6] are $k_{p}=$ $0.33, k_{i}=3.33, g=2$, and $T_{W}=0.1$. It is to be noted that, the eigenvalues are stable with good stability margin for both inductive and capacitive mode of operation of STATCOM.

The transient simulation of the 3 phase model of the STATCOM for step change in the reactive current is shown in Figures 7 and 8.

It can be seen that, transition from capacitive to inductive mode of operation of STATCOM is slow and steady state is reached after $0.2 \mathrm{sec}$ following the step change in reactive



Figure 7: Phase "a" current of STATCOM with nonlinear feedback controller.

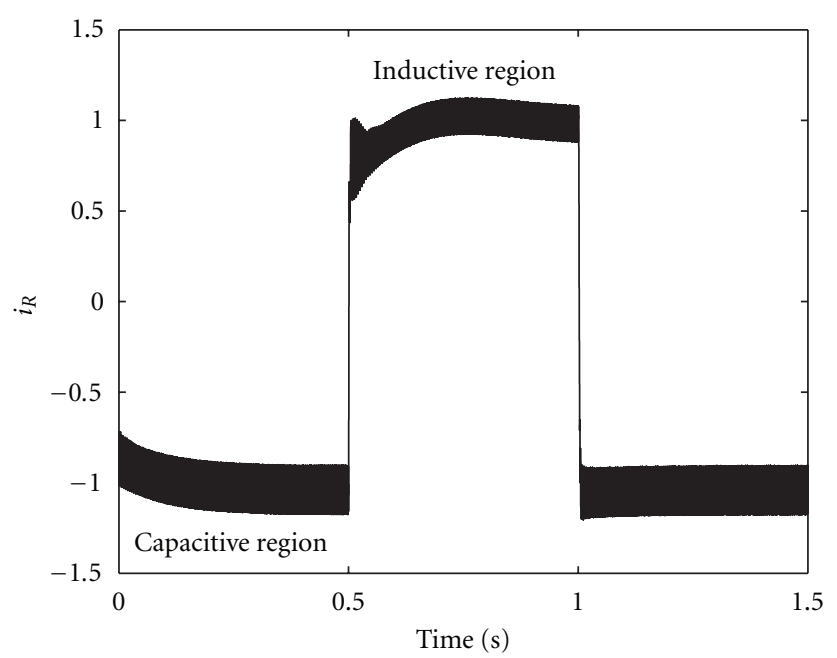

FIGURE 8: Response of STATCOM with nonlinear feedback controller.

current. It is to be noted that, although the system is stable during inductive operation, the transient response of the STATCOM is slow.

Hence there is a need to optimize the controller parameters to improve the transient response of the STATCOM. The optimization of reactive current controller parameters based on GA to improve the transient response will be discussed in the section to follow.

\section{Application of Genetic Algorithm for Controller Parameters Optimization}

4.1. Introduction. GA has been used as optimizing the parameters of control system that are complex and difficult to solve by conventional optimization methods [12].

It maintains a set of candidate solutions called population and repeatedly modifies them. Each member of the 
population is evaluated using a fitness function. The population undergoes reproduction in a number of iterations. One or more parents are chosen stochastically, but strings with higher fitness values have higher probability of contributing the offspring Genetic operators, such as crossover and mutation are applied to parents to produce offspring. The offspring are inserted into the population and the process is repeated.

Given a random initial population, GA operates in cycles called generations as follows.

The basic steps involved in GA are as follows.

Step 1: Begin with a randomly generated population of chromosome-encoded "solutions" to a given problem.

Step 2: Calculate the fitness of each chromosome, where fitness is a measure of how well a member of the population performs at solving the problem.

Step 3: Retain only the fittest members and discard the least fit members.

Step 4: Generate a new population of chromosomes from the remaining members of the old population by applying the operations reproduction, crossover, and mutation.

Step 5: Calculate the fitness of these new members of the population, retain the fittest, discard the least fit, and reiterate the process.

The GA-based optimization guarantees the system stability under varying operating conditions.

4.2. Objective Function. For damping oscillations, the damping factor $\zeta$ of around $10 \%$ to $20 \%$ is considered to be adequate. A damping factor of $10 \%$ would be acceptable to most utilities and can be adopted as the minimum requirement. Further, having the real part of eigenvalue restricted to be less than a value, say $\alpha$, guarantees a minimum decay rate $\alpha$. A value $\alpha=-0.5$ is to be considered adequate for an acceptable settling time. The closed loop mode location should simultaneously satisfy these two constraints for an acceptable small disturbance response of the controlled system.

If all the closed loop poles are located to the left of the contour shown in Figure 9, then the constraints on the damping factor and the real part of eigenvalues are satisfied and a well-damped small disturbance response is guaranteed. This contour is referred to as the $\mathrm{D}$-contour $[3,13]$.

The system is said to be D-stable if it is stable with respect to this D-contour, that is, all its poles lie on the left of this contour. This property is referred to as generalized stability in control literature. This generates a neat specification, the closed loop system should be robustly D-stable, that is, D-stable, for the entire range of operating and system conditions. Hence a system is said to be "robust," if, in spite of changes in system and operating conditions, the closed loop poles remain on the left of the D-contour for the specified range of system and operating conditions.

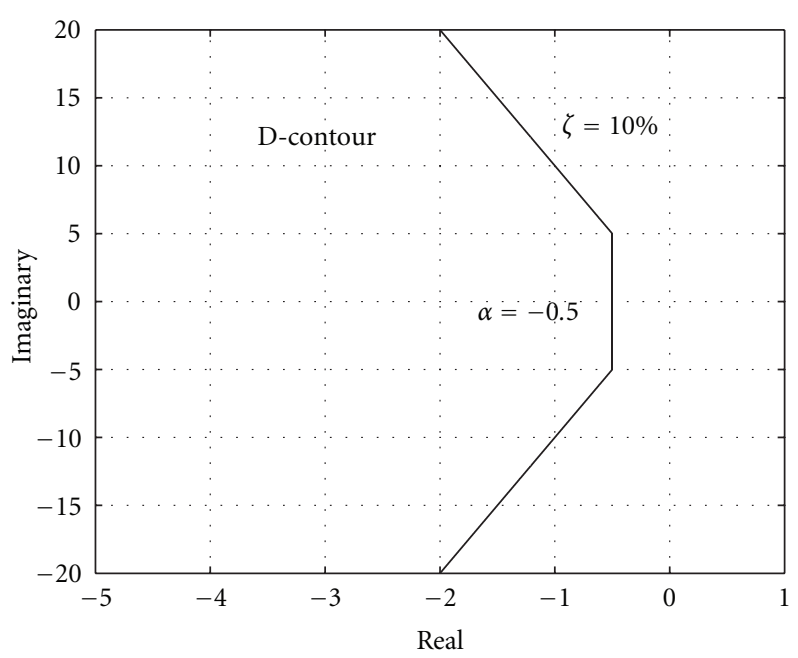

FiguRE 9: D-contour with $\alpha=-0.5$ and $\xi=10 \%$.

The D-contour in Figure 9 can be mathematically described as

$$
f(z)=\operatorname{Re}(z)-\min [-\operatorname{Im}(z), \alpha]=0,
$$

where $z \varepsilon C$ is a point on $\mathrm{D}$-contour and $C$ represents the complex plane.

Define $J$ as

$$
J=\max _{i}\left[\operatorname{Re}\left(\lambda_{i}\right)-\min \{-\zeta|\operatorname{Im}(z)|, \alpha\}\right] \quad i=1,2,3 \ldots n,
$$

where $n$ is the number of eigenvalues. $\lambda_{i}$ is the $i$ th eigenvalue of the system at an operating point. A negative value of $J$ implies that all the eigenvalues lie on the left of the Dcontour. Similarly some or all eigenvalues will lie on the right of the $\mathrm{D}$ contour if $J$ is positive.

On the basis of these facts, objective function $E$ is defined as

$$
\text { Sum Squared Error }(E)=\sum e^{2}
$$

where

$$
e=i_{\text {Rref }}-i_{R}
$$

where $i_{\text {Rref }}$ and $i_{R}$ are the Reactive current reference input and reactive current output of the STATCOM, respectively.

Hence the optimization problem can be stated as follows:

$$
\text { Minimize } E \text {, }
$$

$$
\text { Subjected to } J \leq 0 \text {. }
$$

In addition to this, the boundaries of optimal parameters are

$$
\begin{array}{cc}
g_{\min } \leq g \leq g_{\max } & T_{W_{\min }} \leq T_{W} \leq T_{W_{\max }}, \\
K_{p_{\min }} \leq K_{p} \leq K_{p_{\max }} & K_{i_{\min }} \leq K_{i} \leq K_{p_{\max }} .
\end{array}
$$

Genetic algorithm is adopted to obtain the optimal parameters of PI controller with nonlinear feedback loop $[13,14]$. 
TABLE 3: Parameters used for optimization with genetic algorithm.

\begin{tabular}{lc}
\hline Parameter & Value/type \\
\hline Maximum generations & 25 \\
Population size & 200 \\
Type of selection & Normal geometric $\left[\begin{array}{ll}0 & 0.08\end{array}\right]$ \\
Type of crossover & Arithmetic [4] \\
Type of mutation & Nonuniform $\left[\begin{array}{ll}4 & 20\end{array}\right]$ \\
Termination method & Maximum generation \\
\hline
\end{tabular}

TABLE 4: Eigenvalues with optimal controller parameters based on GA.

\begin{tabular}{lc}
\hline Capacitive region $i_{R}=-1$ & Inductive region $i_{R}=1$ \\
\hline-1856.7 & -2194.6 \\
$-83.949 \pm j 1373.6$ & $-58.401 \pm j 1398.3$ \\
-55.556 & $-32.538 \pm j 4.9879$ \\
-23.842 & \\
\hline
\end{tabular}

The parameters used with GA are given in Table 3. The optimized parameters as obtained by GA are $k_{p}=0.69, k_{i}=$ $16.45, g=2.54$, and $T_{w}=0.018$. The parameters used with GA are given in Table 3.

Eigenvalues of the system with nonlinear feedback and optimized controller parameters are shown in Table 4. Comparing with the eigenvalue results given in Table 2 , it is to be noted that although the damping of critical mode is decreased (in inductive region), the damping of other modes is increased. The GA-based optimization ensures that the system is robustly D-stable for various operating points under consideration.

It can be seen from Figures 10 and 11 that the transition from capacitive to inductive mode of operation of STATCOM is very fast and takes less time, about $0.04 \mathrm{sec}$, to reach steady state.

It is to be noted that the transient response of the STATCOM is significantly improved. The steady state oscillations in the reactive current of Figure 11 are due to harmonics in the converter output voltage. Thus with optimal controller parameters the transient response of the STATCOM is improved.

\section{Conclusion}

In this paper we have presented a systematic method for controller parameter optimization based on genetic algorithm (GA) for the design of STATCOM reactive current controller. The GA-based optimization ensures that the system is robustly D-stable in the entire range of operation and system conditions. The performance of the designed controller is evaluated and it was observed that the STATCOM with optimized controller parameters provides excellent transient response.

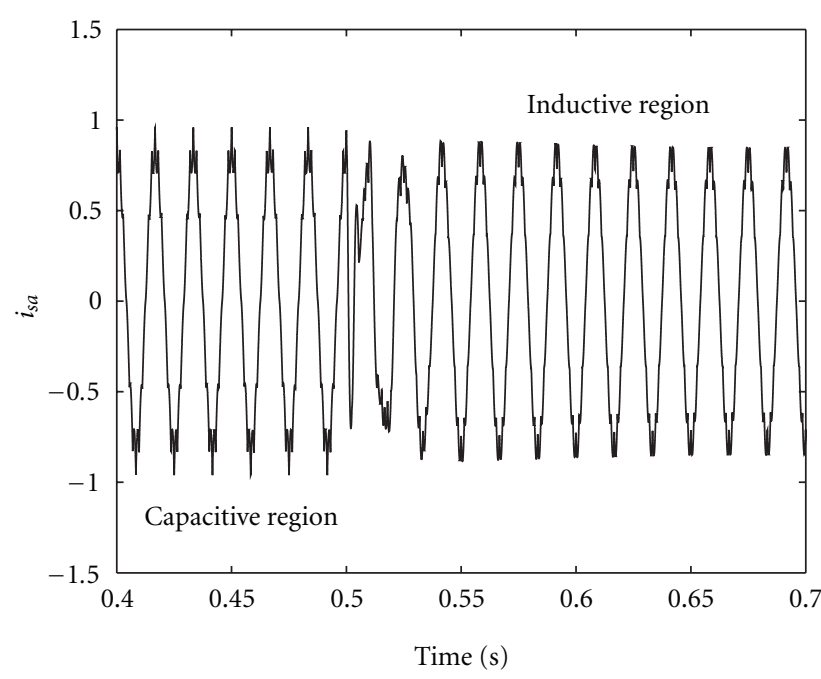

FIGURE 10: Phase "a" current of STATCOM with optimal controller parameters.

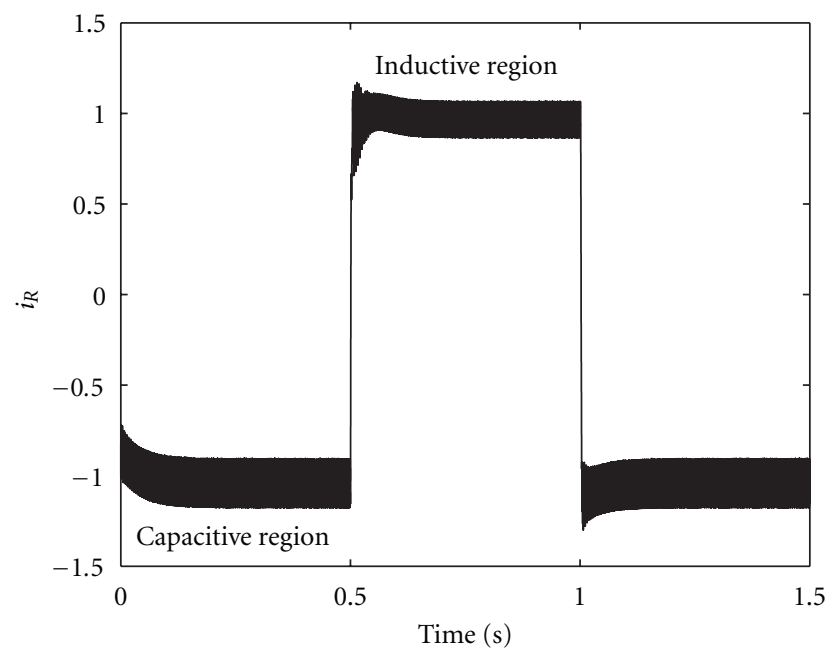

FIGURE 11: Step response with $3 \Phi$ model of STATCOM with optimal controller parameters.

\section{Appendix}

STATCOM data in p.u:

$$
R_{s}=0.01, \quad X_{s}=0.15, \quad R_{p}=78.7, \quad b_{c}=1.136
$$

The suboptimal controller parameters without nonlinear feedback [6] are $k_{p}=0.33$ and $k_{i}=3.33$,

The suboptimal controller parameters with nonlinear feedback [6] are $k_{p}=0.33, k_{i}=3.33, g=2$, and $T_{W}=0.1$.

The optimized parameters as obtained by GA are $k_{p}=$ $0.69, k_{i}=16.45, g=2.54$, and $T_{w}=0.018$.

\section{References}

[1] N. G. Hingorani, "Flexible AC transmission," IEEE Spectrum, vol. 30, no. 4, pp. 40-45, 1993. 
[2] C. Schauder and H. Mehta, "Vector analysis and control of advanced static VAR compensators," IEE Proceedings C, vol. 140, no. 4, pp. 299-306, 1993.

[3] K. R. Padiyar, FACTS Controllers in Power Transmission and Distribution, New age International (P), New Delhi, India, 2007.

[4] Y. Sumi, Y. Harumoto, T. Hasegawa, M. Yano, K. Ikeda, and T. Matsuura, "New static VAR control using force-commutated inverters," IEEE Transactions on Power Apparatus and Systems, vol. 100, no. 9, pp. 4216-4224, 1981.

[5] L. Gyugyi, "Reactive power generation and control by thyristor circuits," IEEE Transactions on Industry Applications, vol. 15, no. 5, pp. 521-532, 1979.

[6] K. R. Padiyar and A. M. Kulkarni, "Design of reactive current and voltage controller of static condenser," International Journal of Electrical Power and Energy Systems, vol. 19, no. 6, pp. 397-410, 1997.

[7] K. R. Padiyar and N. Prabhu, "Design and performance evaluation of subsynchronous damping controller with STATCOM," IEEE Transactions on Power Delivery, vol. 21, no. 3, pp. 1398-1405, 2006.

[8] K. R. Padiyar and V. Swayam Prakash, "Tuning and performance evaluation of damping controller for a STATCOM," International Journal of Electrical Power and Energy Systems, vol. 25, no. 2, pp. 155-166, 2003.

[9] N. Prabhu, Analysis of sub synchronous resonance with voltage source converter based FACTS and HVDC controllers, Ph.D. dissertation, IISc Bangalore, 2004.

[10] K. R. Padiyar, Power System Dynamics: Stability and Control, B.S. Publications, Hyderabad, India, 2nd edition, 2000.

[11] K. R. Padiyar and N. Prabhu, "Analysis of subsynchronous resonance with three level twelve-pulse VSC based SSSC," in Proceedings of the IEEE Conference on Convergent Technologies for Asia-Pacific Region (TENCON '03), vol. 1, pp. 76-80, October 2003.

[12] D. E. Goldberg, Genetic Algorithm in search, Optimization and Machine Learning, Addison Wesley, Reading, Mass, USA, 1989.

[13] R. Singh, A novel approach for tuning of power system stabilizer using genetic algorithm, M.Sc. dissertation, Indian Institute of Science, Bangalore, India, July 2004.

[14] A. L. B. do Bomfim, G. N. Taranto, and D. M. Falcâo, "Simultaneous tuning of power system damping controllers using genetic algorithms," IEEE Transactions on Power Systems, vol. 15, no. 1, pp. 163-169, 2000. 

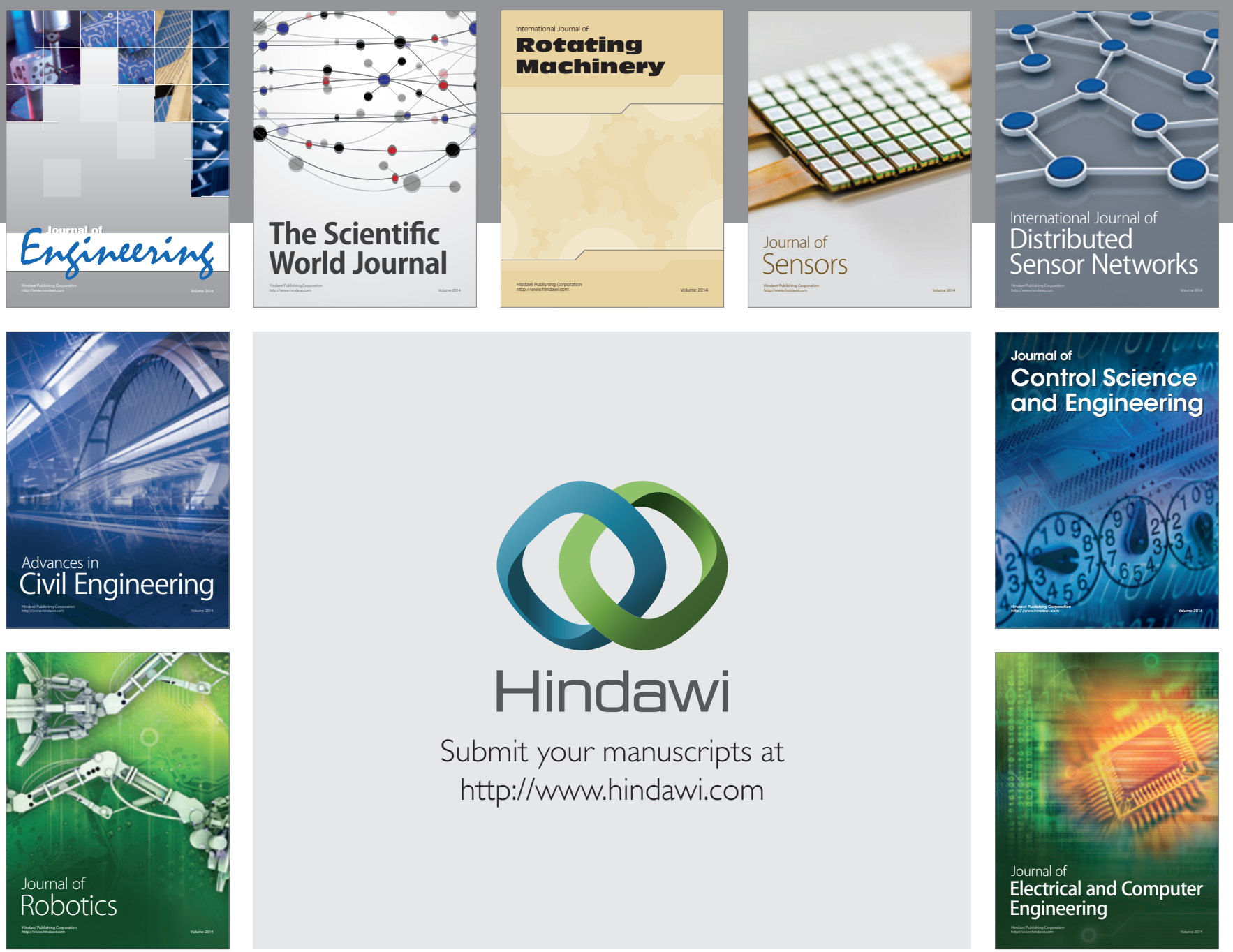

Submit your manuscripts at

http://www.hindawi.com
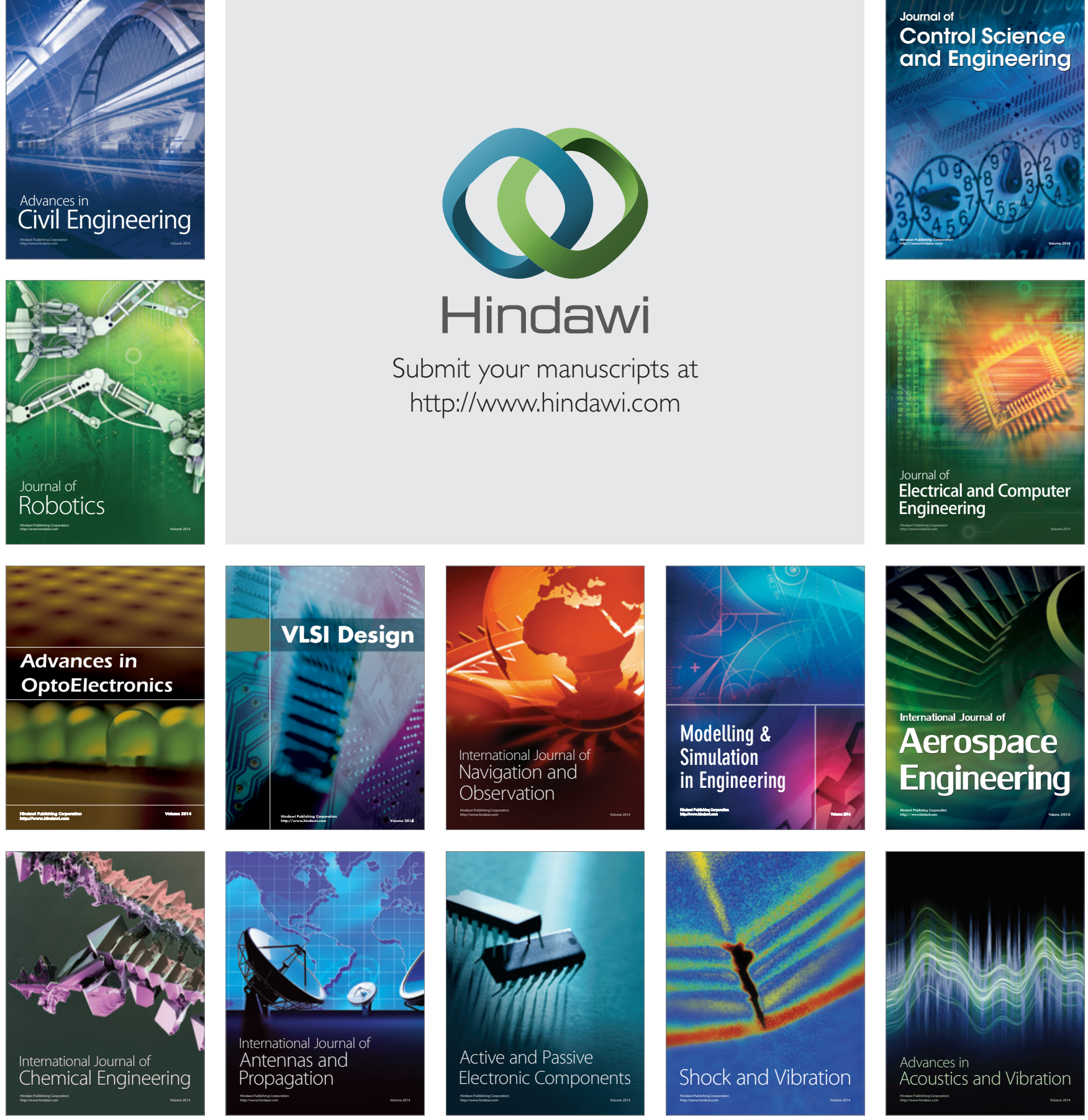